\title{
Too early to declare a general law of social mobility and heritability for education
}

\section{Damien Morris}

Engzell and Tropf (1) find a positive association between intergenerational mobility and heritability for educational attainment. This implies a "general law" that heritability rises whenever social mobility increases and falls whenever it decreases. There are three reasons this conclusion may be premature.

First, the heritability estimates and parent-offspring correlations used are drawn from separate samples. Heritability estimates are drawn from a meta-analysis of twin studies (2) and matched to parent-offspring correlations collated by the World Bank (3).* This raises questions about the validity of the association reported. Conveniently, four of the samples included were from a Norwegian twin study which also reported parent-offspring correlations (4), allowing us to check the accuracy of the matched correlations. The withinsample estimates are substantially and uniformly higher than the matched-sample estimates used by the authors (Table 1).

\begin{tabular}{|c|c|c|c|c|}
\hline \multicolumn{5}{|c|}{$\begin{array}{l}\text { Table 1. Comparing Norwegian twin-parent correlations } \\
\text { from Heath et al (1985) with corresponding parent-offspring } \\
\text { correlations in the World Bank's GDIM. }\end{array}$} \\
\hline \multirow[b]{2}{*}{ Relationship } & \multicolumn{2}{|c|}{ 1940-49 Cohort } & \multicolumn{2}{|c|}{ 1950-1959 Cohort } \\
\hline & Heath et al & GDIM & Heath et al & GDIM \\
\hline Son-Mother & 0.61 & 0.19 & 0.51 & 0.16 \\
\hline Son-Father & 0.64 & 0.21 & 0.55 & 0.30 \\
\hline Daughter-Mother & 0.57 & 0.34 & 0.55 & 0.27 \\
\hline Daughter-Father & 0.79 & 0.41 & 0.60 & 0.31 \\
\hline
\end{tabular}

These discrepancies give reason to be cautious of results drawn from the matched data. Indeed, if we repeat the analysis with these revised Norwegian figures, the headline association between heritability and social mobility disappears. The regression slope of heritability on the parent-offspring correlation levels off (Fig.1A), and the standardized 
regression coefficient (controlling for gender) attenuates from -0.512 (clustered SE $=0.142$ ) to -0.208 (CSE $=0.202)$, becoming non-significant. $†$

Second, the authors' analysis (OLS regression) risks giving undue influence to heritability estimates from small samples: equal weight is given to samples containing 200 twin pairs as samples containing 11,000 (2). Fig.1B compares the original regression slope with a WLS regression slope from the same (unadjusted) data. It uses the same inverse-variance method for precision-weighting heritability estimates as was used in the meta-analysis from which Engzell and Tropf drew their twin data (2). A Again, the regression slope levels off, and the standardized regression coefficient (controlling for gender) attenuates to non-significance (beta $=-0.301$, CSE $=0.255)$.

A

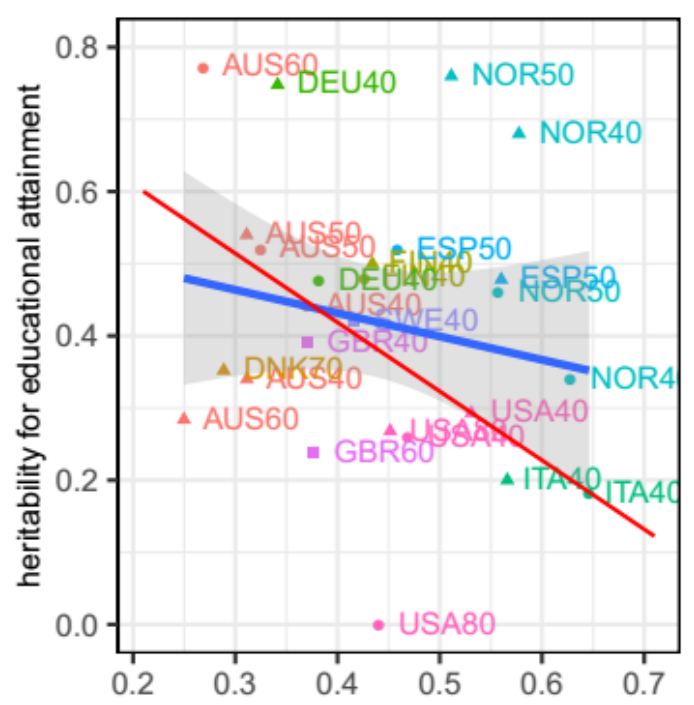

B

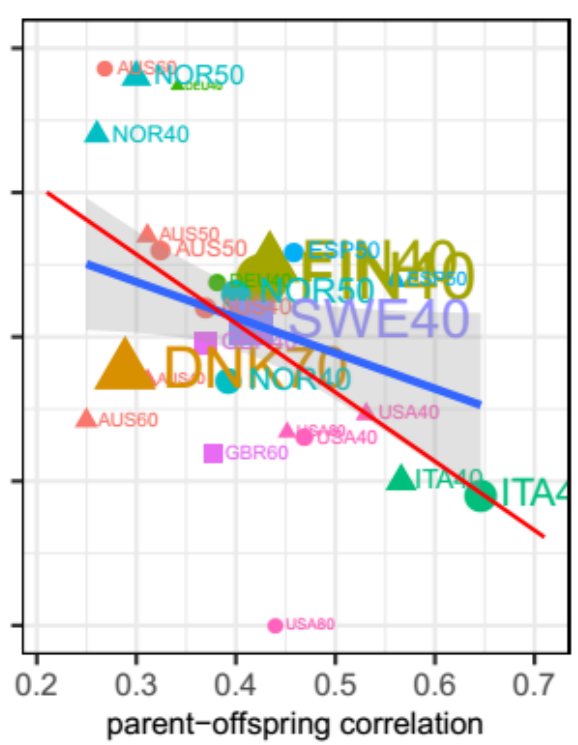

C

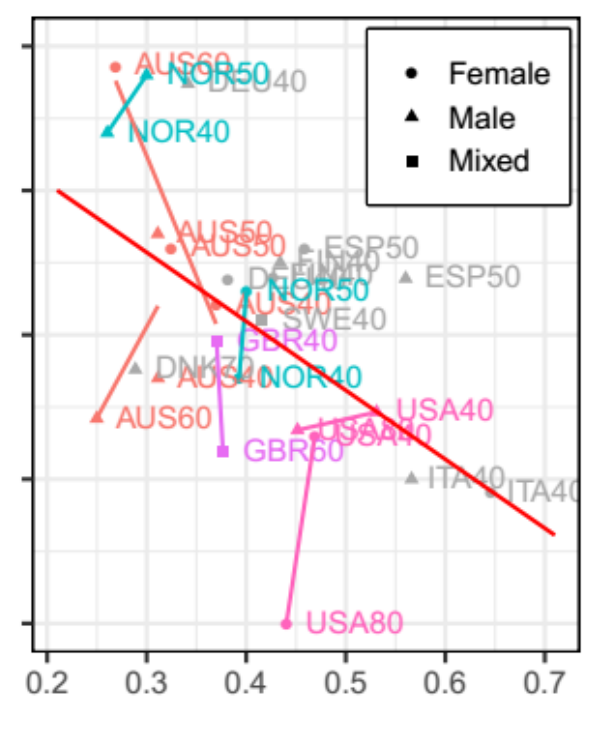

Fig.1: Three sensitivity tests of the association between heritability and parent-offspring correlations reported in Engzell and Tropf (2019): A) substituting Norwegian parent-offspring correlations from Heath et al (1985), B) precisionweighting heritability estimates, C) within-country association testing for each gender. Engzell and Tropf's original OLS regression slope is shown in red. Country codes are preserved from Fig.1 in Engzell and Tropf.

Third, if the original result for social mobility and heritability is a "general law", it should hold for men and women living in different times and places. However, several studies have found that notionally progressive educational and welfare reforms have had quite different effects on heritability for men and women in different countries (4-9). This suggests the relationship between social mobility and heritability might also be different in each case. To explore this, we plotted the regression of heritability on parent-offspring correlations for each gender in each country (Fig. 1C). This generates seven regression lines, five of which 
run in the opposite direction to the original line for the aggregated data (1). While the data on each gender/country combination are too sparse to draw strong conclusions, the effect found in the aggregated data might not generalize to its subgroups and might thus be an instance of Simpson's Paradox (10).

It was innovative of Engzell and Tropf (1) to test whether intergenerational mobility could predict heritability for educational attainment. However, we cannot be confident of this relationship until this question is revisited with: a) samples containing data on twins and parents/offspring; b) models that precision-weight those samples; and c) models that test the consistency of the relationship across salient subgroups.

\section{Acknowledgements}

This contribution has benefitted from communications with Dr Stuart J. Ritchie.

\section{Footnotes}

* Engzell and Tropf matched twin heritability estimates from Branigan et al (2013) (2) to parent-offspring correlations in the GDIM (3), matching twins to offspring based on nationality, gender, and approximate decade of birth (the midrange of birth years in each twin sample).

† When reporting their main results, Engzell and Tropf (2019) (1) use the GDIM correlation between offspring and their most educated parent (3). This correlation was not reported in Heath et al (1985) (4). Therefore, when substituting in data from that study, we have used the mean of the correlation between twins and their mothers and twins and their fathers. For all other samples, we continued to use the GDIM correlation for most educated parent.

‡This specific analysis was pre-registered. More information about this inverse variance weighting methodology can be read in the pre-registration document at: https://osf.io/pk9my/. Other supplementary materials, including code for reproducing this analysis, are available at the same link.

Email: damien.morris@kcl.ac.uk

Author contributions: DM analyzed the data and wrote the letter.

The author declares no conflict of interest. 


\section{References}

1. P. Engzell, F. C. Tropf, Heritability of education rises with intergenerational mobility. Proc. Natl. Acad. Sci. 116, 25386-25388 (2019).

2. A. R. Branigan, K. J. McCallum, J. Freese, Variation in the Heritability of Educational Attainment: An International Meta-Analysis. Soc. Forces 92, 109-140 (2013).

3. What is the Global Database on Intergenerational Mobility (GDIM)? World Bank (May 31, 2020). https:/www.worldbank.org/en/topic/poverty/brief/what-is-the-globaldatabase-on-intergenerational-mobility-gdim

4. A. C. Heath, et al., Education policy and the heritability of educational attainment. Nature 314, 734-736 (1985).

5. K. Tambs, J. M. Sundet, P. Magnus, K. Berg, Genetic and environmental contributions to the covariance between occupational status, educational attainment, and IQ: A study of twins. Behav. Genet. 19, 209-222 (1989).

6. P. Lichtenstein, N. L. Pedersen, G. E. McClearn, The Origins of Individual Differences in Occupational Status and Educational Level: A Study of Twins Reared Apart and Together. Acta Sociol. 35, 13-31 (1992).

7. L. A. Baker, S. A. Treloar, C. A. Reynolds, A. C. Heath, N. G. Martin, Genetics of educational attainment in Australian twins: Sex differences and secular changes. Behav. Genet. 26, 89-102 (1996).

8. K. Silventoinen, J. Kaprio, E. Lahelma, Genetic and Environmental Contributions to the Association Between Body Height and Educational Attainment: A Study of Adult Finnish Twins. Behav. Genet. 30, 477-485 (2000).

9. L. Colodro-Conde, F. Rijsdijk, M. J. Tornero-Gómez, J. F. Sánchez-Romera, J. R. Ordoñana, Equality in Educational Policy and the Heritability of Educational Attainment. PLoS ONE 10 (2015).

10. R. Kievit, W. E. Frankenhuis, L. Waldorp, D. Borsboom, Simpson's paradox in psychological science: a practical guide. Front. Psychol. 4 (2013). 